\title{
More than a feeling: understanding function and health related quality of life after pediatric neurocritical illness
}

\author{
Jessica M. Jarvis ${ }^{1,2}$ and Ericka L. Fink ${ }^{2,3^{*}}$ (D) \\ C 2021 Springer Science+Business Media, LLC, part of Springer Nature and Neurocritical Care Society
}

As more children survive neurocritical illness, stakeholders are fostering a focus on improving long-term survivorship for children and their families. This rational, yet ambitious, undertaking is further complicated by how a successful survivorship is defined and measured [1,2]. Performance-based assessment of physical, emotional, and cognitive function informs referral to therapeutic services, such as physical therapy or behavioral health, with specific needs changing longitudinally [3]. Alternatively, optimizing an individual's quality of life (QOL) is arguably the ultimate priority for healthcare providers and families, after a desired goal of survival is assured $[4,5]$. Generally speaking, QOL comprises an individual's perception of their position in life within their culture and in relation to their goals, expectations, standards, and concerns [5]. Health researchers often focus on the aspects of QOL that relate to how an individual feels about the status of their health, thus termed health related QOL (HRQOL). The relationship between these performance-based/clinician-observed measures and self-reported measures of QOL in children with neurocritical illness is important to explore to improve understanding of the impact of pediatric critical illness on the population and how we can help individuals achieve their recovery goals. The ability to identify children at risk for poor HRQOL outcomes is beneficial for the purposes of shared decision-making, setting future expectations and

\footnotetext{
*Correspondence: finkel@ccm.upmc.edu

${ }^{2}$ Safar Center for Resuscitation Research, University of Pittsburgh School of Medicine, Pittsburgh, PA, USA

Full list of author information is available at the end of the article
}

This commentary is related to the original article available at https://doi. org/10.1007/s12028-021-01271-8. goals, and anticipating rehabilitation needs. Thus, the clinical implementation of routine longitudinal assessments that include both performance and HRQOL selfreport outcomes to support patients and families through neurocritical illness recovery is innovative and research in this area shows it is vital.

In this issue of Neurocritical Care, Holding et al. [6] used validated measures to explore the relationship between health function, via the Functional Status Scale (FSS), and HRQOL, assessed via the PedsQL Generic Core Scales (aged 2-18 years) and Infant Scales (aged 1-24 months), in 195 children who survived neurocritical illness. The FSS was scored by physicians (unclear if by chart review or examination) at baseline, hospital discharge, and first visit to their center's innovative Pediatric Critical Care and Neurotrauma Recovery Program clinic (median time to follow-up 53 days). The proxy (parent/ guardian) completed the HRQOL measure at the time of the clinic visit (no baseline assessment). The authors hypothesized that decreased functional status from baseline to hospital discharge would predict worse overall and individual domain HRQOL scores at the clinic visit.

They found $43 \%$ of proxies reported HRQOL $\geq 1$ standard deviation lower than age-matched healthy children. Also, FSS scores were reported as three groups with reference to change from baseline: no score change (58\%), $1-2$ point increase (26\%), and $\geq 3$ point increase $(16 \%)$. Their key finding was that change in FSS $\geq 3$ at discharge was associated with worse overall HRQOL and worse physical HRQOL but not other HRQOL domains after adjustment for confounders in multivariable regression models. In addition, female sex was associated not only with lower HRQOL overall but also each domain. Although limited, prior literature on sex differences in

\section{Springer}


pediatric HRQOL support this finding, with sex discrepancies increasing as children age $[7,8]$. The authors posit that this finding could be due to hormonal differences or societal influences on gender behavior norms, with boys and parents of boys being less likely to report experiencing difficulties. It is also possible that proxies may perceive HRQOL of their sons and daughters differently.

This study's findings are well aligned with emerging literature on pediatric critical care survivorship $[9,10]$. In multicenter prospective studies of children with community-acquired septic shock and respiratory failure, 35\% and $20 \%$, respectively, had worse HRQOL compared with their baseline status [11]. How should clinicians interpret this work? First, although the constructs are related, we should take care not to directly equate an individual child's functional status with their perceived HRQOL $[5,12,13]$. Second, individual child and family preferences and goals should drive medical decision-making $[1,14]$. Third, consider that both function and satisfaction with functioning may change over time during the recovery period with rehabilitation and that children may view the latter differently than their parents/guardians (and ask the child whenever possible). Fourth, we should strive to implement routine clinical longitudinal assessments of function and HRQOL to adapt our plan of care to the child's new level of functioning and to identify and address unmet medical and social needs that contribute to a thriving survivorship for children and their families [15].

Further, some experts have reservations regarding the extent to which the measure used for this study captures HRQOL alone versus functional performance $[5,16,17]$. For example, asking the child how often it is hard for them to run is more aligned with a self-reported measure of physical functioning, whereas asking if they are satisfied with their ability to run is more aligned with HRQOL. This distinction is highlighted by their finding that, of the multiple multivariable regression models completed for each of the HRQOL domains, change in FSS score significantly improved the physical domain model only, and is further supported by their finding that children without a change in FSS score experienced lower HRQOL scores in emotional, social, and school domains.

These findings suggest there may be other factors influencing HRQOL aside from new impairments in health function, such as sleep, family functioning, and the lived environment. Other studies by this research group report $>50 \%$ of children experienced sleep disturbances 3 months post $\mathrm{ABI}$, and fatigue severity was associated with worse QOL 20 years post pediatric TBI $[18,19]$. LeBlond and colleagues [20] recently reported that among children $\leq 4$ years, family functioning was significantly associated with HRQOL among TBI or orthotic injury populations 6 months after injury. Lastly, when exploring the link between functional status and functional performance or HRQOL, the environment in which the child lives may be a mediating factor and has been associated with parents' satisfaction with their child's participation in daily life activities within the home 6 months after pediatric critical illness [21, 22].

To summarize, Holding et al. [6] have provided foundational knowledge on the lived experiences of children as perceived by their parent/guardian and robustly highlighted the need for continued assessment and support post neurocritical illness. As we think about neurocritical illness survivorship as a continuum versus a single time point (i.e., hospital discharge), resources, such as interdisciplinary post-PICU follow-up programs, may be one instrumental approach toward assuring that all families are equipped to maximize their child's HRQOL during recovery and as they continue to develop across their life span [23]. The landscape of pediatric critical care is changing, and we must be willing to think flexibly, work collaboratively, and continuously evaluate our processes of care and advocate for what is best for our patients to achieve our ultimate goal of supporting children to live the best version of their lives.

\section{Author details \\ ${ }^{1}$ Department of Physical Medicine and Rehabilitation, University of Pittsburgh School of Medicine, Pittsburgh, PA, USA. ${ }^{2}$ Safar Center for Resuscitation Research, University of Pittsburgh School of Medicine, Pittsburgh, PA, USA. ${ }^{3}$ Department of Critical Care Medicine, UPMC Children's Hospital of Pitts- burgh, Pittsburgh, PA, USA.}

Source of support

National Institutes of Health T32 HD040686 (JMJ) and NINDS R01 NS096714 (ELF).

Conflict of interest

The authors declare no conflicts of interest.

\section{Publisher's Note}

Springer Nature remains neutral with regard to jurisdictional claims in published maps and institutional affiliations.

Received: 20 April 2021 Accepted: 4 May 2021

Published online: 20 July 2021

\section{References}

1. Fink EL, Maddux AB, Pinto $N$, et al. A core outcome set for pediatric critical care. Crit Care Med. 2020;48(12):1819-28. https://doi.org/10.1097/CCM. 0000000000004660.

2. Maddux AB, Pinto N, Fink EL, et al. Postdischarge outcome domains in pediatric critical care and the instruments used to evaluate them: a scoping review. Crit Care Med. 2020;48(12):e1313-21. https://doi.org/10.1097/ ccm.0000000000004595.

3. Slomine BS, McCarthy ML, Ding R, et al. Health care utilization and needs after pediatric traumatic brain injury. Pediatrics. 2006; https://doi.org/10. 1542/peds.2005-1892.

4. Fayed BN, Cameron S, Fraser D, et al. Priority outcomes in critically ill children: a patient and parent perspective. Crit Care Res. 2020;29(5):94-103. 
5. Ow N, Appau A, Matout M, Mayo NE. What is QOL in children and adolescents with physical disabilities? A thematic synthesis of pediatric QOL literature. Qual Life Res. 2021; https://doi.org/10.1007/s11136-021-02769-6.

6. Holding EZ, Turner EM, Hall TA, Leonard S, Bradbury KR, Williams CN. The association between functional status and health-related quality of life following discharge from the pediatric intensive care unit. Neurocrit Care. 2021. https://doi.org/10.1007/s12028-021-01271-8.

7. Michel G, Bisegger C, Fuhr DC, Abel T. Age and gender differences in health-related quality of life of children and adolescents in Europe: a multilevel analysis. Qual Life Res. 2009;18(9):1147-57. https://doi.org/10. 1007/s11136-009-9538-3.

8. Bisegger C, Cloetta B, von Rueden U, et al. Health-related quality of life: gender differences in childhood and adolescence. Soz Praventivmed. 2005;50(5):281-91. https://doi.org/10.1007/s00038-005-4094-2.

9. Manning JC, Pinto NP, Rennick JE, Colville G, Curley MAQ. Conceptualizing post intensive care syndrome in children - the PICS-p framework* Pediatr Crit Care Med. 2018;19(4):298-300. https://doi.org/10.1097/PCC. 0000000000001476

10. Choong K, Fraser D, Al-Harbi S, et al. Functional recovery in critically ill children, the "Wee-Cover" multi-centre study. Pediatr Crit Care Med. 2018;19(2):145-54.

11. Zimmerman JJ, Banks R, Berg RA, et al. Trajectory of mortality and health related quality of life morbidity following community-aquired pediatric septic shock. Crit Care Med. 2021;48(3):329-37. https://doi.org/10.1097/ CCM.0000000000004123.

12. Fayed N, Cohen E, Houtrow A. Quality of life cannot be predicted from a brain scan. Dev Med Child Neurol. 2020;62(4):412. https://doi.org/10. 1111/dmen.14484.

13. Schneider JW, Gurucharri LM, Gutierrez AL, Gaebler-Spira DJ. Healthrelated quality of life and functional outcome measures for children with cerebral palsy. Dev Med Child Neurol. 2001;43(9):601-8. https://doi.org/ 10.1111/j.1469-8749.2001.tb00242.x

14. Jarvis JM, Kaelin VC, Anaby D, Teplicky R, Khetani MA. Electronic participation-focused care planning support for families: a pilot study. Dev Med Child Neurol. 2020;62(8):954-61. https://doi.org/10.1111/dmcn.14535.

15. Jarvis JM, Gurga A, Lim H, et al. Caregiver strategy use to promote children's home participation after pediatric critical illness. Arch Phys Med
Rehabil. 2019;100(11):2144-50. https://doi.org/10.1016/j.apmr.2018.09. 015.

16. Ravens-Sieberer U, Erhart M, Wille N, Wetzel R, Nickel J, Bullinger M. Generic health-related quality-of-life assessment in children and adolescents: methodological considerations. Pharmacoeconomics. 2006;24(12):1199-220. https://doi.org/10.2165/00019053-20062 4120-00005.

17. Fayed N, De Camargo OK, Kerr E, et al. Generic patient-reported outcomes in child health research: a review of conceptual content using World Health Organization definitions. Dev Med Child Neurol. 2012;54(12):1085-95. https://doi.org/10.1111/j.1469-8749.2012.04393.x.

18. Botchway EN, Godfrey C, Ryan NP, et al. Sleep disturbances in young adults with childhood traumatic brain injury: relationship with fatigue, depression, and quality of life. Brain Inj. 2020;34(12):1579-89. https://doi. org/10.1080/02699052.2020.1832704.

19. Williams CN, Hartman ME, McEvoy CT, et al. Sleep wake disturbances after acquired brain injury in children surviving critical care. Pediatr Neurol. 2020;103:43-51. https://doi.org/10.1016/j.pediatrneurol.2019.08.010.

20. LeBlond E, Smith-Paine J, Narad M, et al. Understanding the relationship between family functioning and health-related quality of life in very young children with moderate-to-severe TBI. Clin Neuropsychol. 2021. https://doi.org/10.1080/13854046.2021.1881163.

21. Khetani MA, Albrecht E, Jarvis JM, Pogorzelski D, Cheng E, Choong K. Determinants of change in home participation among critically ill children. Dev Med Child Neurol. 2018;60(8):793-800. https://doi.org/10.1111/ dmcn. 13731.

22. Jarvis JM, Fayed N, Fink EL, Choong K, Khetani MA. Caregiver dissatisfaction with their child's participation in home activities after pediatric critical illness. BMC Pediatr. 2020;20(1):415. https://doi.org/10.1186/ s12887-020-02306-3.

23. Wainwright MS, Grimason M, Goldstein J, et al. Building a pediatric neurocritical care program: a multidisciplinary approach to clinical practice and education from the intensive care unit to the outpatient clinic. Semin Pediatr Neurol. 2014;21(4):248-54. https://doi.org/10.1016/j.spen.2014.10. 006. 